\title{
Comparison of event landslide inventories: the Pogliaschina catchment test case, Italy
}

\author{
A. C. Mondini ${ }^{1}$, A. Viero ${ }^{2}$, M. Cavalli ${ }^{2}$, L. Marchi ${ }^{2}$, G. Herrera $^{3}$, and F. Guzzetti ${ }^{1}$ \\ ${ }^{1}$ Consiglio Nazionale delle Ricerche, Istituto di Ricerca per la Protezione Idrogeologica, via della Madonna Alta 126, \\ 06128 Perugia, Italy \\ ${ }^{2}$ Consiglio Nazionale delle Ricerche, Istituto di Ricerca per la Protezione Idrogeologica, Corso Stati Uniti 4, \\ 35127 Padua, Italy \\ ${ }^{3}$ Instituto Geológico y Minero de España, Ríos Rosas, 23 28003, Madrid, Spain \\ Correspondence to: A. C. Mondini (alessandro.mondini@irpi.cnr.it)
}

Received: 20 January 2014 - Published in Nat. Hazards Earth Syst. Sci. Discuss.: 4 February 2014

Revised: 5 May 2014 - Accepted: 8 May 2014 - Published: 15 July 2014

\begin{abstract}
Event landslide inventory maps document the extent of populations of landslides caused by a single natural trigger, such as an earthquake, an intense rainfall event, or a rapid snowmelt event. Event inventory maps are important for landslide susceptibility and hazard modelling, and prove useful to manage residual risk after a landslide-triggering event. Standards for the preparation of event landslide inventory maps are lacking. Traditional methods are based on the visual interpretation of stereoscopic aerial photography, aided by field surveys. New and emerging techniques exploit remotely sensed data and semi-automatic algorithms. We describe the production and comparison of two independent event inventories prepared for the Pogliaschina catchment, Liguria, Northwest Italy. The two inventories show landslides triggered by an intense rainfall event on 25 October 2011, and were prepared through the visual interpretation of digital aerial photographs taken 3 days and 33 days after the event, and by processing a very-high-resolution image taken by the WorldView- 2 satellite 4 days after the event. We compare the two inventories qualitatively and quantitatively using established and new metrics, and we discuss reasons for the differences between the two landslide maps. We expect that the results of our work can help in deciding on the most appropriate method to prepare reliable event inventory maps, and outline the advantages and the limitations of the different approaches.
\end{abstract}

\section{Introduction}

A landslide inventory map shows the location of mass movements that have left discernable features in an area (Pašek, 1975; Hansen, 1984; McCalpin, 1984; Wieczorek, 1984; Guzzetti et al., 2000, 2012). Landslide event inventories show the landslides caused by a single trigger, such as an intense rainstorm, an earthquake, or a rapid snowmelt event, and provide information useful to model landslides at the basin scale, to assess sediment budgets, and to train and validate landslide susceptibility or hazard models (Borga et al., 2002; Remondo et al., 2003; van Westen et al., 2003; Ercanoglu and Gokceoglu, 2004; Ayalew and Yamagishi, 2005; Weirich and Blesius, 2007; Lira et al., 2013). Landslide event inventories can also be used to determine the residual risk posed by the new landslides, and represent a useful tool for rescue efforts and recovery actions.

Event landslide inventory maps can be prepared using different techniques (Guzzetti et al., 2012), and the selection of the appropriate technique depends on the purpose of the inventory, the size of the area covered and the time required to complete the inventory, the skills and experience of the investigators, and the available resources (Guzzetti et al., 2000, 2012; van Westen et al., 2006). All the available techniques have a degree of subjectivity (Guzzetti et al., 2012). Traditional methods are based primarily on the visual interpretation of stereoscopic aerial photographs aided by field surveys. These methods are intrinsically subjective, and the results depend - among other factors - on the skills and experiences of the investigators. New methods use automatic or 
semi-automatic procedures based on the selection of training areas (Mondini et al., 2011, 2013), or on the application of pre-defined classification rules (Martha et al., 2010; Stumpf and Kerle, 2011). Selection of the training areas and definition of the classification rules introduce subjectivity in the new methods (Guzzetti et al., 2012).

The quality of a landslide inventory depends on its accuracy, and on the type and certainty of the information shown in the map. Criteria to assess the quality and completeness of landslide inventories are lacking (Galli et al., 2008; Guzzetti et al., 2012). When two or more inventories are available for the same area, comparison of the inventories makes it possible to establish a degree of (relative) confidence on the landslide maps. Only a limited number of studies have tackled the problem of the comparison of two or more landslide maps (e.g., Carrara et al., 1992; Guzzetti et al., 2000; Brardinoni et al., 2003; Ardizzone et al., 2007; van Westen et al., 2006; Galli et al., 2008). This is unexpected, given the importance of establishing the quality of a landslide inventory for scientific investigations and practical purposes. However, the availability of two or more independent landslide maps for the same area is rare, limiting the possibility to perform the comparisons.

In this work, we present two event landslide inventory maps prepared just after a landslide-triggering rainfall event by two independent teams that have used consolidated and innovative mapping techniques, including (i) the visual interpretation of aerial imagery, and (ii) the semi-automatic classification of very high resolution (VHR) satellite images. The two inventory maps are compared quantitatively, and reasons for the differences are discussed, outlining advantages and limitations of the different mapping techniques.

The paper is organized as follows. In Sects. 2 and 3, we give a brief description of the study area and the landslidetriggering event, respectively. In Sect. 4 we present the imagery and the ancillary data used to prepare the two event inventories. This is followed, in Sect. 5, by a description of the methods used to prepare the two inventories and a description of the obtained inventories. Next, in Sect. 6, we compare the two inventories, and we measure their similarities using different metrics. In Sect. 7, we discuss the results of the comparison, outlining strengths and weaknesses of the two adopted mapping techniques. In Sect. 8, we conclude summarizing the lessons learnt.

\section{Study area}

The Pogliaschina catchment drains into the Vara River, in the Northwest Apennines, northern Italy (Fig. 1a). The Vara River valley occupies a tectonic depression originated from the combination of two main tectonic phases associated with the formation of the Apennines mountain range. A compressive phase, Cretaceous to Eocene in age, was followed by an extensional phase, Oligocene to Holocene in age, that in the area produced a SE-NW trending graben (Raggi, 1985;

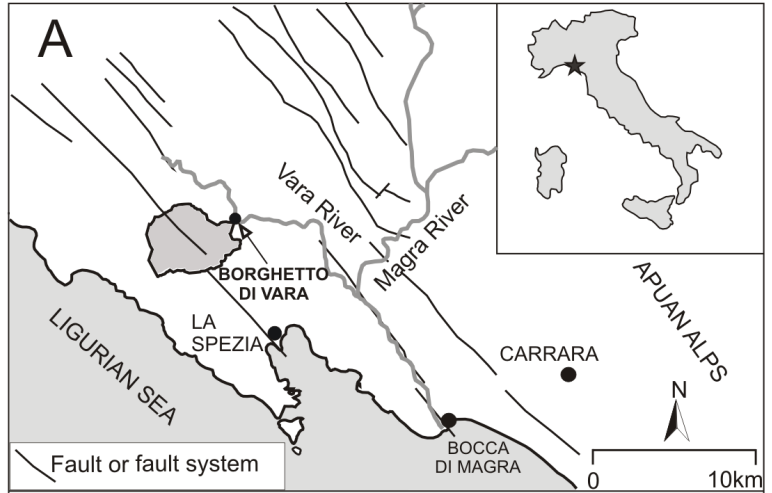

B

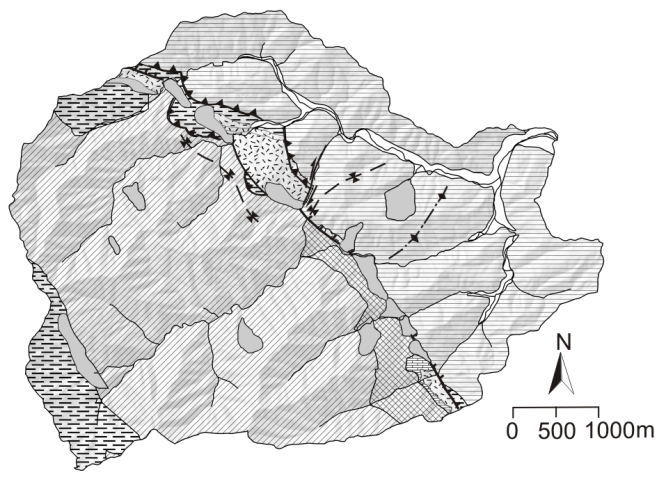

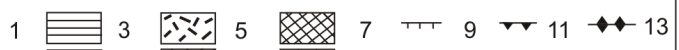

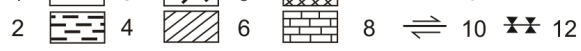

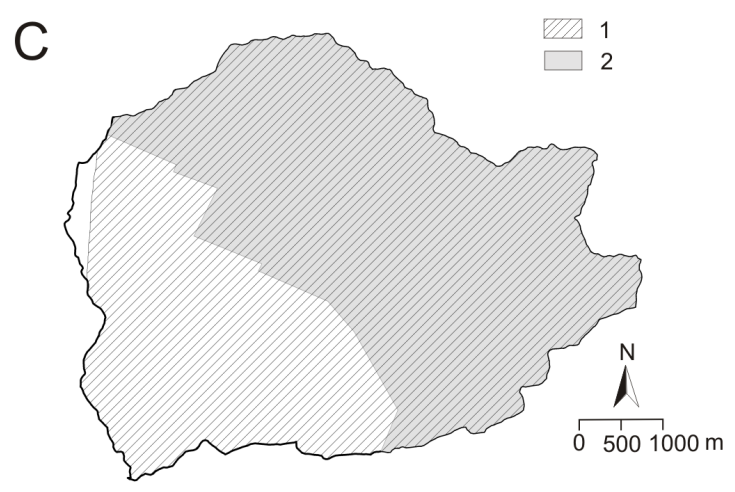

Figure 1. The Pogliaschina catchment. (A) Location map. Dark grey area shows location of the Pogliaschina catchment. (B) Geological map: (1) fluvial deposit, (2) landslide deposit, (3) Monte Gottero Flysch, (4) clay-rich rocks, (5) igneous and metamorphic rocks, (6) Macigno Flysch, (7) Scaglia Toscana, (8) Maiolica, (9) normal fault, (10) strike-slip fault, (11) thrust fault, (12) anticline axis, (13) syncline axis. (C) Coverage of satellite and aerial images.

Bini et al., 2009) (Fig. 1b). During the extensional phase the graben opened progressively, and post-orogenic continental sediments deposited in the tectonic depression. In the area, two geological units superimposed along a SE-NW regional thrust cover a metamorphic basement. Carbonate rocks overlaid by siltstones and mudstones pertaining to the Scaglia 
Toscana and the Macigno formations crop out to the west of the thrust. To the east of the thrust crops out the Canetolo Unit, consisting of carbonates and sandstones covered by ophiolites, and by turbidites pertaining to the Monte Gottero Flysch. A few large, ancient landslides were recognized in the area (ISPRA, 2013), mostly along the regional tectonic contact (Fig. 1b).

Elevation in the $25.1 \mathrm{~km}^{2}$ area ranges between 96 and $721 \mathrm{~m}$, with an average elevation of $337 \mathrm{~m}$. Terrain slope averages $28.3^{\circ}$, with local differences controlled by the regional tectonic lineaments. In the upper part of the catchment terrain is steep, with slopes ranging between 25 and $40^{\circ}$, and in the lower part of the catchment terrain is gentler, with slopes ranging between 15 and $25^{\circ}$. Climate is Mediterranean, with dry summers, and most of the precipitation falling in October and November, and a mean annual cumulated precipitation of $1500 \mathrm{~mm}$. The area is predominantly forested, with around $50 \%$ of the catchment covered by hardwood (mostly chestnut, Castanea sativa), $21 \%$ by coniferous (maritime pine, Pinus pinaster), and $17 \%$ by mixed forest. Vineyards, olive groves and other agricultural areas occupy approximately $10 \%$ of the catchment. Urban areas are small, and they concentrate at lower elevations. Borghetto di Vara, the main village in the area, is located near the confluence between the Pogliaschina torrent and the Vara River.

\section{Landslide-triggering rainfall event}

On 25 October 2011, a very high intensity storm hit the Tyrrhenian coast between Liguria and Tuscany. The Pogliaschina catchment lies in the area that received the largest amount of rainfall, with the most intense precipitation occurring from 10:00 a.m. to 04:00 p.m., CET. Analysis of weather radar (Marchi et al., 2013) and rain gauge data revealed significant variations in the cumulated rainfall in the catchment. The largest cumulated rainfall (almost $500 \mathrm{~mm}$ ) was observed in the central and the southern parts of the catchment, whereas the northern part experienced a smaller amount of rainfall (about $250 \mathrm{~mm}$ ). The maximum hourly rainfall intensity in the catchment reached $150 \mathrm{~mm} \mathrm{~h}^{-1}$. The intense rainfall triggered widespread shallow landslides and caused a major flash flood along the Pogliaschina torrent and its tributaries (Fig. 2). The event caused six fatalities in the Pogliaschina catchment. Flooding of the village of Borghetto di Vara killed four people, and a landslide that hit a hamlet in the central part of the catchment killed two people.

\section{Available imagery}

We obtained a pair of stereoscopic WorldView-2 images taken on 29 October 2011, four days after the landslide triggering rainfall event. The stereoscopic images consist of two bundles acquired with different off nadir angles (6.6 and $32.2^{\circ}$, respectively). Both bundles have a $0.5 \mathrm{~m}$ ground

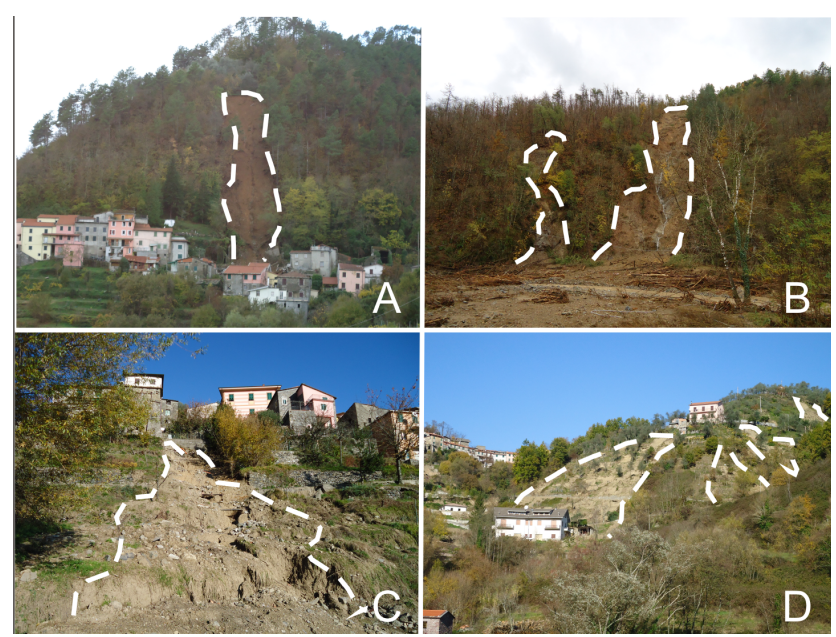

Figure 2. Examples of landslide types mapped in the Pogliaschina catchment: (A) and (B) are earthflows, (C) and (D) are soil slips.

sampling distance (GSD) panchromatic band, and four $2 \mathrm{~m}$ GSD multispectral (blue, green, red, NIR) bands. The satellite images were provided in UTM WGS84 coordinates, and were not orthorectified. We further obtained (i) digital aerial photographs (24 frames, each covering approximately $1.0 \mathrm{~km} \times 1.3 \mathrm{~km}$ ) taken on 28 October 2011 , and (ii) orthophotographs (26 frames, each covering $0.8 \mathrm{~km} \times 1.0 \mathrm{~km}$ ) acquired on 28 November 2011. The panchromatic stereoscopic satellite images cover almost the entire study area, and the post-event orthophotographs and the aerial photographs collectively cover $62.5 \%$ of the study area (Fig. 1c). We consider the two sets of digital images (satellite and aerial) equivalent for the production of event landslide inventory maps (Nale, 2002; Weirich and Blesius, 2007; Fiorucci et al., 2011; Guzzetti et al., 2012). Three pre-event VHR images acquired on 28 October 2003, 6 February 2006, and 20 July 2011, and an additional post-event image acquired on 16 May 2012 were available from Google Earth $^{\circledR}$.

\section{Event landslide inventory maps}

Two separate groups of investigators prepared the two event landslide inventories independently. The first event inventory, hereafter referred to as the "photo-interpreted" (PI) inventory, was obtained through the visual interpretation of the available aerial photographs, orthophotographs, and panchromatic stereoscopic satellite images. The second event inventory, hereafter referred to as "semi-automatic" (SA) inventory, was obtained through the semi-automatic classification of the satellite images.

\subsection{Photo-interpreted landslide inventory map}

For the study area, we organized in a geographical information system (GIS) the pre- and the post-event digital orthophotographs, together with a geological map at $1: 50000$ 
scale, a land cover map at $1: 10000$ scale, topographic base maps at $1: 10000$ scale, and a $10 \mathrm{~m}$ resolution digital elevation model (DEM). These cartographic data are available from the Liguria Region geo-portal (http://www.cartografia. regione.liguria.it).

Next, the aerial photographs were geo-referenced and added to the GIS. To geo-reference the aerial photographs, we searched pairs of ground control points (GCPs) in the post-event digital photographs and in the pre-event orthophotographs and topographic base maps, and we performed a first-order polynomial interpolation using a minimum of six pairs of GCPs. Identification of the GCPs was straightforward in the urban area where points were selected along the roads and in the buildings, and more difficult in the forested terrain that covers most of the study area. The root mean square error for the interpolation ranged from $2 \mathrm{~m}$ (in urban areas) to $20 \mathrm{~m}$ (in forested terrain), with an average of $7 \mathrm{~m}$.

Next, we compared visually the pre-event orthophotographs acquired in 2006 with a satellite image acquired on 20 July 2011, two months before the event, available through Google Earth $^{\odot}$. The visual comparison of the two images made it possible to verify that no significant landslidetriggering event had occurred in the area between 2006 and the date of the satellite image (20 July 2011). Anecdotal information confirmed that landslides did not occur between 20 July 2011 and the date of the landslide triggering rainfall event, 25 October 2011.

We prepared the PI inventory by interpreting visually the post-event orthophotographs and the digital aerial photographs, collectively covering $62.5 \%$ of the study area (Fig. 1c). For most of the remaining $37.5 \%$ of the study area we interpreted visually the stereoscopic, panchromatic satellite images, which were also used to check locally individual landslides or groups of landslides identified and mapped on the post-event orthophotographs and the digital aerial photographs. To recognize the landslides we adopted standard photo-interpretation criteria based on the recognition of a set of characteristics that could be identified visually on the images, including shape, size, photographic colour, tone, mottling, texture, pattern of objects, site topography, and local setting (Antonini et al., 2002; Guzzetti et al., 2012). The digital aerial photographs taken on 28 October 2011 are of high quality and resolution, and made it possible to detect and map consistently very small soil slips and areas that suffered surface erosions. The orthophotographs flown on 28 November 2011 were taken with less favourable lighting conditions, making the detection and mapping of the landslides more difficult and locally less accurate. Further, natural soil erosion from landslide scars, and artificial sediment removal occurred in the period between the date of the rainfall event (25 October 2011) and the date of the orthophotographs (28 November 2011), obliterating partially or completely some of the soil slips and the landslide deposits. Visual interpretation of the aerial and the satellite imagery was aided by the results of field surveys carried out to make the interpreters familiar with the landslides and the landscape where the slope failures had occurred, and to resolve local ambiguities and visual classification problems. Field surveys lasted about two weeks, and were carried out immediately after the event and one year later, between October 2012 and January 2013.

With a maximum depth of two metres, all landslides were classified as shallow and grouped into four classes: (1) translational slides, (2) earth flows, (3) soil slips, and (4) rotational slides. Field surveys made it possible to recognize the different types of landslides, and to collect soil samples to characterize residual soils in the landslide scarps. In the study area, translational and rotational slides are located mainly at the foot of the slopes along main and secondary streams. Earth flows exhibit elongated shapes, are frequently channelled along secondary streams, and exhibit longer run-out distances than the translational and the rotational slides. Soil slips are the first evolutionary stage of the other landslide types, and exhibit irregular surfaces covered locally by grass and shrubs. Soil slips are abundant in terraced slopes, in low gradient areas where vegetation is scarce, in cultivated areas, and in abandoned cultivated areas. This finding is in agreement the observations of other authors (Canuti et al., 2004; Conti and Fagarazzi, 2004; Tarolli et al., 2014) on the relevance of processes associated to agricultural land abandonment, including lack of maintenance of dry-stone walls in terraced areas and the clogging of minor drainage channels, on soil degradation and the initiation of shallow slope instability.

The PI inventory (Fig. 3a) shows 588 landslides, ranging in size from $A_{\mathrm{L}}=11 \mathrm{~m}^{2}$ to $A_{\mathrm{L}}=13795 \mathrm{~m}^{2}$, average $A_{\mathrm{L}}=$ $743 \mathrm{~m}^{2}$, for a total landslide area $A_{\mathrm{LT}}=436787 \mathrm{~m}^{2}, 1.8 \%$ of the catchment area (Table 1). The majority of the failures are earth flows $(53 \%)$ with an average $A_{\mathrm{L}}=788 \mathrm{~m}^{2}$. Soil slips are the second most abundant type of failure (36\%), with an average $A_{\mathrm{L}}=782 \mathrm{~m}^{2}$. Translational $(9.5 \%)$ and rotational $(1.5 \%)$ slides are the less frequent types of landslides, and have the smallest average $A_{\mathrm{L}}=520 \mathrm{~m}^{2}$. Compared to the earth flows, slides are wider and exhibit a shorter run-out distance.

\subsection{Semi-automatic landslide inventory map}

For the preparation of the semi-automatic (SA) inventory (Fig. 3b) we used the multispectral bundle acquired by the WorldView-2 satellite with an off-nadir angle of $6.6^{\circ}$ on 29 October 2011. An attempt to pan-sharp the image resulted in a poor ("noisy") image, not suitable for the analysis (Wald et al., 2007). We corrected geometrically the multispectral bundle through an orthorectification transformation, including a change of projection and datum. For the purpose, we used the available DEM, and we co-registered the image to the topographic base maps at $1: 10000$ scale using 15 GCPs. We checked the co-registration using 10 additional GCPs. Visual inspection of the satellite image superimposed on the 

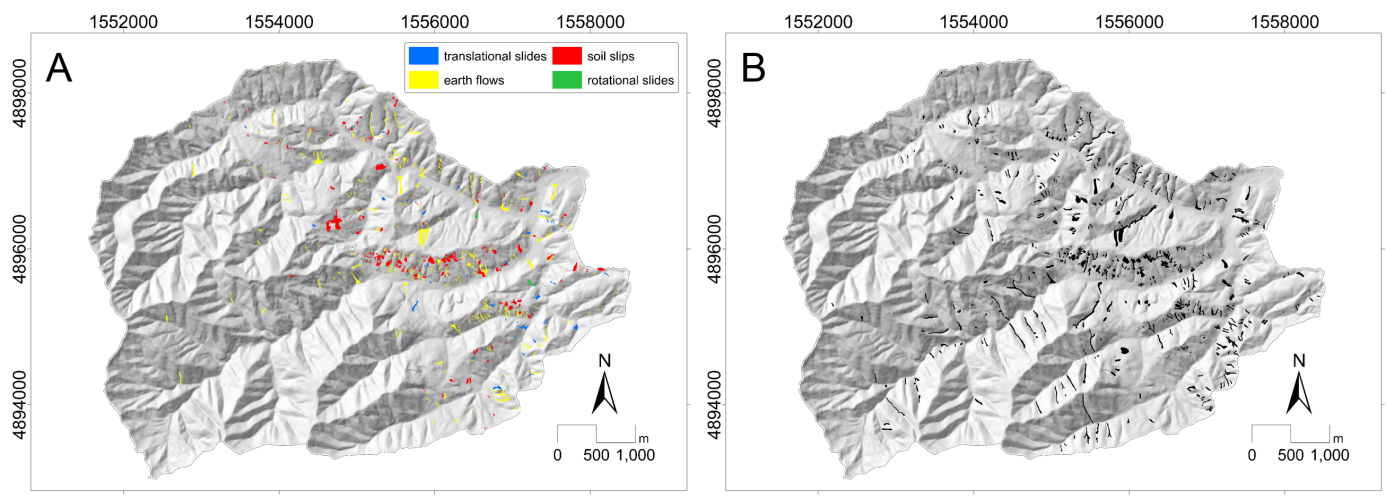

Figure 3. Event landslide inventory maps. (A) Photo-interpreted (PI) event landslide inventory map obtained through the visual interpretation of post-event orthophotographs and digital aerial photographs. (B) Semi-automatic (SA) event landslide inventory map obtained through the analysis of a post-event WorldView-2 satellite image.

Table 1. Statistics for the two original event landslide inventories. (A) Photo-interpreted landslide inventory map, PI, (B) semi-automatic landslide inventory map, SA, (C) photo-interpreted landslide inventory map without soil slips, (D) semi-automatic landslide inventory map without soil slips.

\begin{tabular}{lccccc}
\hline & & A & B & C & D \\
\hline Number of mapped landslides & $\#$ & 588 & 537 & 385 & 365 \\
Minimum landslide area & $\mathrm{m}^{2}$ & 11 & 30 & 12 & 30 \\
Maximum landslide area & $\mathrm{m}^{2}$ & 13795 & 7870 & 10009 & 7870 \\
Mean landslide area & $\mathrm{m}^{2}$ & 743 & 713 & 722 & 674 \\
Standard deviation of landslide area & $\mathrm{m}^{2}$ & 1160 & 983 & 1.036 & 1012 \\
Total landslide area & $\mathrm{m}^{2}$ & 436787 & 382935 & 277996 & 245828 \\
Proportion of landslide area & $\%$ & 1.8 & 1.5 & 1.1 & 1.0 \\
\hline
\end{tabular}

topographic base map reveals a good co-registration. For practical purposes, most of the GCPs were selected where terrain is flat, e.g. in the valley bottom. This geographically biased selection reduced the quality of the co-registration where terrain is steep. The geographical scale of the SA inventory is the same scale as the topographic base map used for the co-registration $(1: 10000)$. This scale is consistent with the image GSD.

We examined the frequency distribution of the different bands in the co-registered satellite image. The blue band exhibits two distinct peaks (Fig. 4), and the red, green, and NIR bands (not shown) exhibited similar distributions. We investigated the reason for the bimodal shape of the frequency of the blue band (and the other bands), and found that the first peak (at digital number, $\mathrm{DN}=130$ ) was due to pixels located in shadowed areas, and the second peak $(\mathrm{DN}=175)$ corresponded to pixels located in non-shadowed areas. We decided to treat separately the shadowed and the non-shadowed areas, and we split the image accordingly, with the nonshadowed areas covering $68 \%$ of the image and the shadowed areas covering the remaining $32 \%$ of the area (Fig. 5). To divide the image we used a single threshold selected to coincide with the saddle point in the frequency curve for the blue band (Fig. 4).

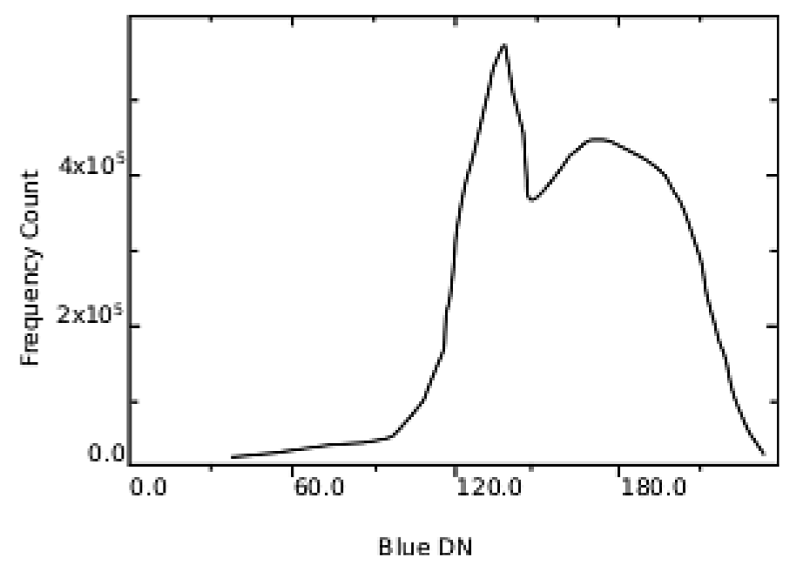

Figure 4. Frequency distribution of the digital number (DN) values of the WorldView-2 satellite image in the blue channel.

We classified the non-shadowed part of the image (Fig. 5) using a supervised maximum likelihood classifier. For the landslide land cover class, we trained the classifier using seven regions of interest (ROIs) located in landslide areas. These ROIs were selected where the soil was bare or the vegetation was sparse, assuming that landslides had removed the dense and uniform vegetation that covered the slopes before 


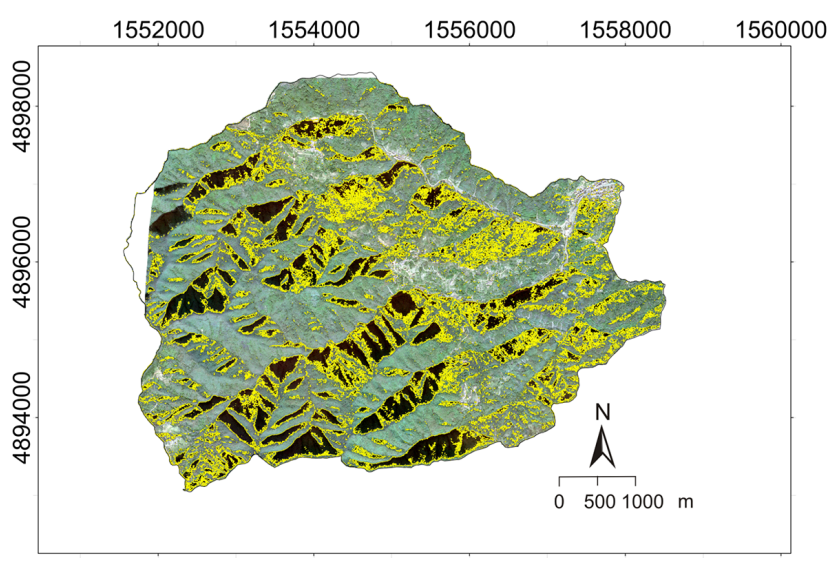

Figure 5. WorldView-2 satellite image. Yellow polygons show the areas considered as shadowed ( $32 \%$ of total).

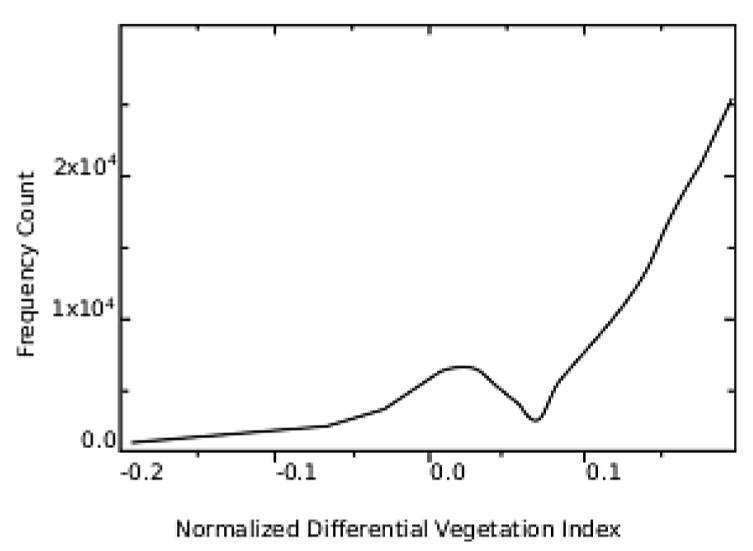

Figure 6. Frequency distribution of the NDVI values in shadowed areas.

the event. We selected 12 supplementary ROIs to represent three additional land cover classes: vegetation (forest, six ROIs), water (one ROI), and urban areas (five ROIs). We classified the shadowed part of the image (Fig. 5) by thresholding the frequency curve (Fig. 6) of the normalized difference vegetation index (NDVI) that exhibits a single peak around zero. We examined a pre-event image available on Google Earth $^{\odot}$, and found that shadows in the post-event image were in steep and densely forested terrain. We assumed that values of NDVI forming the peak (Fig. 6) were due to lack of vegetation that was stripped from the steep slopes by the new event landslides. We confirmed this assumption by analysing visually a post-event image clear of shadows available from Google Earth $^{\odot}$. Finally, to reduce the "saltand-pepper" effect typical of pixel-based classifications, we identified clusters of six or fewer pixels classified as landslide (landslide free) areas and classified them as landslide free (landslide) areas ("clumping"). We acknowledge that the selection of a minimum threshold of six pixels was subjective, but we maintain that it was in agreement with field evidence on the size and shape of the mapped landslides.
The SA inventory (Fig. 3b) shows 537 landslides, ranging in size from $A_{\mathrm{L}}=30 \mathrm{~m}^{2}$ to $A_{\mathrm{L}}=7870 \mathrm{~m}^{2}$, average $A_{\mathrm{L}}=$ $713 \mathrm{~m}^{2}$, for a total landslide area $A_{\mathrm{LT}}=382935 \mathrm{~m}^{2}, 1.5 \%$ of the total catchment area (Table 1). The semi-automatic classification procedure did not allow for a classification of the individual landslides, which were all classified as shallow landslides in the SA inventory.

\section{Comparison of the two event inventories}

Figure 3 portrays the two event landslide inventory maps, and Table 1 lists descriptive statistics for the two inventories. The time needed for preparing the two inventories was different. Production of the PI inventory (Fig. 3a) required about 20 days of work of one interpreter, whereas production of the SA inventory (Fig. $3 b$ ) required $24 \mathrm{~h}$ of work, including $2 \mathrm{~h}$ for the acquisition and the organization of the ancillary data, $3 \mathrm{~h}$ for the necessary image pre-processing, $18 \mathrm{~h}$ for the classification, and $1 \mathrm{~h}$ for the post-processing. This is a ratio of $0.15(24 \mathrm{~h} / 160 \mathrm{~h})$ in favour of the SA inventory.

In both inventories, landslides were particularly abundant in olive groves and vineyards, and where previously cultivated areas were abandoned and colonized by sparse woods. About $65 \%$ of the landslides originated from the sandy soils that cover the Monte Gottero Formation, and $16 \%$ from the soils that mantle the Macigno Formation. The remaining landslides $(19 \%)$ detached from cohesive rock types or alluvial deposits which are less susceptible to surface instabilities and cover limited areas of the study area. The abundance of landslides in soils originated from the Monte Gottero Formation is evidence of the high susceptibility of these rocks. This was confirmed by laboratory tests. Residuals soils taken in the Monte Gottero Formation exhibited an average friction angle of $30^{\circ}$, lower than the average value of residual soils covering the Macigno Formation $\left(34^{\circ}\right)$. Soils in the Macigno Formation exhibited larger plasticity and compressibility than soils in the Monte Gottero Formation. Cohesion was found to be lower $\left(1.96 \mathrm{~N} \mathrm{~m}^{-2}\right)$ in soils in the Monte Gottero Formation and higher in soils in the Macigno Formation $\left(4.90 \mathrm{~N} \mathrm{~m}^{-2}\right)$.

We compared the two inventories, examining differences and similarities in: (i) the number, size, and total area of the event landslides, (ii) the spatial density of the event landslides, and (iii) the probability density of the event landslide areas. We further investigated differences in landslide surface spectral response for the two event inventories.

The PI inventory shows $8.7 \%$ more landslides (588 vs. $537)$, and $12.6 \%$ more landslide area $\left(4.37 \times 10^{5} \mathrm{~m}^{2}\right.$ vs. $3.82 \times 10^{5} \mathrm{~m}^{2}$ ) than the SA inventory. The proportion of landslide area in the catchment is $1.8 \%$ for the PI inventory, and $1.5 \%$ for the SA inventory. The largest landslide in the PI inventory extends for $1.4 \times 10^{4} \mathrm{~m}^{2}$, twice the size of the largest landslide in the SA inventory $\left(7.9 \times 10^{3} \mathrm{~m}^{2}\right)$, and the smallest landslide in the SA inventory $\left(3.0 \times 10^{1} \mathrm{~m}^{2}\right)$ is three 
times larger than the smallest landslide in the PI inventory $\left(1.1 \times 10^{1} \mathrm{~m}^{2}\right)($ Table 1$)$.

We determined the spatial density of the event landslides (number of event landslides per unit area) in the two event inventories using a low-pass Gaussian filter moved across the two landslide maps where the landslide presence is initially marked by the value one and landslide absence by the value zero. We then determined the spatial correlation between the two landslide density maps calculating the correlation coefficient $\operatorname{cc}_{\rho_{1} \rho_{2}}$,

$\operatorname{cc}_{\rho_{1} \rho_{2}}=\frac{\operatorname{cov}\left(\rho_{1}, \rho_{2}\right)}{\sigma_{\rho_{1}} \sigma_{\rho_{2}}}$,

where $\rho_{1}$ and $\rho_{2}$ are the two spatial landslide densities, cov is the covariance matrix, and $\sigma_{\rho_{1}}$ and $\sigma_{\rho_{2}}$ are the standard deviations of $\rho_{1}$ and $\rho_{2}$, respectively. We obtained a correlation coefficient $\operatorname{cc}_{\rho_{1} \rho_{2}}=0.57$, indicative of a moderate spatial correlation between the two event inventory maps.

To investigate further the degree of spatial matching (or mismatching) between the two event inventories, we computed the map mismatching index $E$ proposed by Carrara et al. (1992),

$$
E=\frac{\left(A_{\mathrm{PI}} \cup A_{\mathrm{SA}}\right)-\left(A_{\mathrm{PI}} \cap A_{\mathrm{SA}}\right)}{\left(A_{\mathrm{PI}} \cup A_{\mathrm{SA}}\right)} ; 0 \leq E \leq 1,
$$

where $A_{\mathrm{PI}}$ and $A_{\mathrm{SA}}$ are the area, and $\cup$ and $\cap$ are the geometric union and the intersection of the two inventories. We also computed the map-matching index $M$ introduced by Galli et al. (2008) and Fiorucci et al. (2011),

$M=1-E ; 0 \leq M \leq 1$.

We obtained $E=0.71$ and $M=0.29$, which are similar to the values obtained e.g. by Carrara et al. (1992) $(0.52 \leq E \leq$ $0.78)$, Galli et al. (2008) $(0.66 \leq E \leq 0.81)$, and by Fiorucci et al. (2011) $(E>0.75)$ in similar physiographical environments.

To compare the probability density of the event landslide areas we modelled the empirical data with the double Pareto function proposed by Stark and Hovius (2001). For the purpose, we used the Web Processing Service (WPS) available at http://geomorphology.irpi.cnr.it/tools/ statistcs-of-landslide-sizes. The WPS determines the parameters that control the double Pareto density function through maximum likelihood estimation (MLE) (Fisher, 1922a, b; White et al., 2008). Results of the modelling are shown in Fig. 7, and summarized in Table 2. Inspection of Fig. 7a reveals that the probability density for the two inventories overlaps for large landslides $\left(A_{\mathrm{L}}>3.0 \times 10^{2} \mathrm{~m}^{2}\right)$. This is confirmed by the similarity of the scaling exponents for the tails of the distributions, i.e. $\alpha=1.39$ for the PI inventory and $\alpha=1.31$ for the SA inventory. The peak ("rollover") in the density functions is more evident for the SA inventory and less distinct for the PI inventory, and it occurs at a
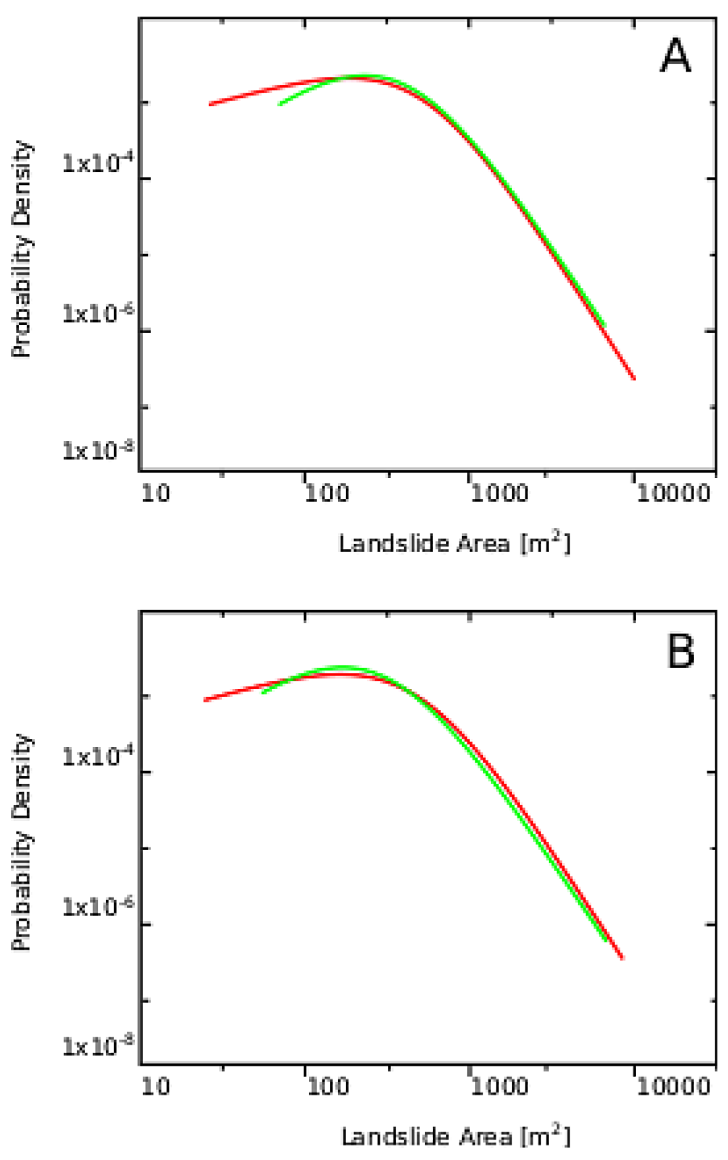

Figure 7. Dependence of landslide probability densities $p$ ( $y$ axis) on landslide area $A_{\mathrm{L}}$ ( $x$ axis) for the two event landslide inventories. Curves show double Pareto density functions (Stark and Hovius, 2001) for the photo-interpreted (PI, green) inventory shown in Fig. 3a, and for the semi-automatic (SA, red) inventory shown in Fig. 3b. (A) Density functions for the original (complete) inventories. (B) Density functions for the modified (reduced) inventories. See text for explanation.

slightly larger landslide size for the SA inventory $\left(132 \mathrm{~m}^{2}\right)$ than for the PI inventory $\left(105 \mathrm{~m}^{2}\right)$. Considering the uncertainties associated with the mapping and the determination of the density functions, we consider the difference in the landslide size for the two rollovers to be negligible. We note that the density function deviates for very small landslides $\left(A_{\mathrm{L}}<1.5 \times 10^{2} \mathrm{~m}^{2}\right)$. This is confirmed by the values of the scaling exponents for the left tail of the distributions, i.e. $\beta=1.41$ for the PI inventory and $\beta=2.07$ for the SA inventory. We consider this as evidence of a difference of the two event inventories, and therefore of the two mapping techniques in detecting and mapping the very small landslides.

We studied the spectral response of the landslides in the two event inventories by examining the NDVI. The NDVI is related to the presence or absence of vegetation, and the semi-automatic classification methods rely on the presence or absence of vegetation for detecting and mapping the landslides (Guzzetti et al., 2012). In the GIS, we overlaid the map 
Table 2. Parameters for the "double Pareto" probability density function used to model the distribution of the landslide areas in the two inventories. (A) Photo-interpreted landslide inventory map, PI, (B) semi-automatic landslide inventory map, SA, (C) photo-interpreted landslide inventory map without soil slips, (D) semi-automatic landslide inventory map without soil slips.

\begin{tabular}{|c|c|c|c|c|c|}
\hline & & $\mathrm{A}$ & $\mathrm{B}$ & $\mathrm{C}$ & $\mathrm{D}$ \\
\hline Scaling exponent " $\alpha$ " & & $1.39 \pm 0.11$ & $1.31 \pm 0.13$ & $1.37 \pm 0.15$ & $1.27 \pm 0.14$ \\
\hline Scaling exponent " $\beta$ " & & $1.42 \pm 0.21$ & $2.07 \pm 0.59$ & $1.44 \pm 0.29$ & $2.13 \pm 0.78$ \\
\hline Rollover & $\mathrm{m}^{2}$ & 105 & 132 & 106 & 112 \\
\hline$T$ (starting point for $\alpha)$ & $\mathrm{m}^{2}$ & $367 \pm 84$ & $237.5 \pm 93$ & $363 \pm 114$ & $195 \pm 97$ \\
\hline
\end{tabular}

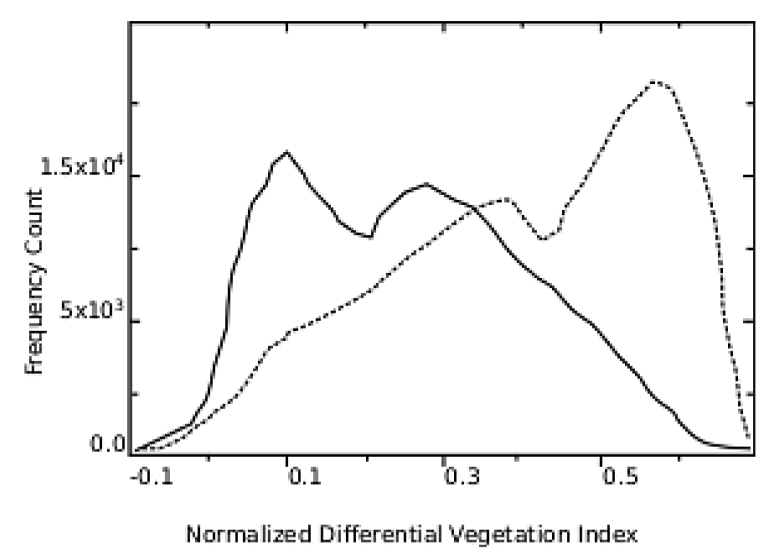

Figure 8. Distribution of NDVI values in the areas covered by the two original event inventories. Dotted line shows the photointerpreted (PI) inventory portrayed in Fig. 3a. Continuous line shows the semi-automatic (SA) inventory shown in Fig. $3 b$.

of the NDVI obtained by processing the multi-spectral information captured by the WorldView-2 satellite image taken on 29 October 2011 on the two event inventories, and we obtained the frequency distributions of the NDVI for the event landslides in the two inventories (Fig. 8). The frequency distribution of the NDVI for the PI inventory is bimodal, with two distinct modes for NDVI $\cong 0.34$, corresponding to sparse vegetation, and for NDVI $\cong 0.50$, corresponding to dense vegetation. The frequency distribution of the NDVI for the SA inventory also exhibits two modes, but for different values of the NDVI; a mode for NDVI $\cong 0.24$, for sparse vegetation, and a second mode for NDVI $\cong 0.10$, representing bare ground where the vegetation is not present.

Visual and GIS comparison of the two event inventories revealed that the main differences between the two maps consisted in (i) landslides in shadow areas that are shown in the SA inventory and are often not shown in the PI inventory, and (ii) soil slips that are shown in the PI inventory and are not shown in the SA inventory. Other minor differences are caused by co-registration problems between the satellite and the aerial images, due to local deformations of the aerial photographs and to the different spatial resolutions. In the shadowed areas, visual interpretation of the aerial and the satellite images was not capable of capturing the landslides, whereas the semi-automatic procedure exploited the multi- spectral information captured by the satellite image to detect and map the landslides. Lack of soil slips in the SA inventory is due primarily to the reduced resolution of the satellite image, compared to the aerial photography and the orthophotographs used for the visual interpretation. The higher resolution of the aerial imagery allowed the interpreter to recognize very shallow soil slips with irregular shapes.

We then removed from the PI inventory all soil slips, and from the SA inventory all landslides in shadow areas, and all landslides that overlapped with soil slips in the PI inventory. We then repeated the quantitative comparison of the two inventories. Removal of the soil slips excluded 203 landslides (36\%) from the PI inventory, and 172 landslides (32\%) from the SA inventory. Without the soil slips, the PI inventory shows $5.2 \%$ more landslides (385 vs. 365 ) and $11.9 \%$ more landslide area $\left(2.78 \times 10^{5} \mathrm{~m}^{2}\right.$ vs. $\left.2.45 \times 10^{5} \mathrm{~m}^{2}\right)$ than the SA inventory. The average percentage of landslide area deceased to $1.1 \%$ for the PI inventory, and to $1.0 \%$ for the SA inventory. The largest landslide extends for $1.0 \times 10^{4} \mathrm{~m}^{2}$ in the PI inventory, and remains $7.9 \times 10^{3} \mathrm{~m}^{2}$ in the SA inventory. The smallest landslide in the SA inventory $\left(3.0 \times 10^{1} \mathrm{~m}^{2}\right)$ is three times larger than the smallest landslide in the PI inventory $\left(1.2 \times 10^{1} \mathrm{~m}^{2}\right)$ (Table 1$)$.

The correlation between the spatial density of the two inventories, measured by correlation coefficient (Eq. 1), increased to $\mathrm{cc}_{\rho_{1} \rho_{2}}=0.76$, and the spatial mismatching index (Eq. 2) decreased significantly to $E=0.59(M=0.41)$. The probability density of the event landslide areas (Fig. 7b) remained similar, with the scaling exponents $\alpha$ only slightly reduced (1.37 for the PI inventory, 1.27 for the SA inventory). The "rollover" (peak) for the PI inventory remained the same $\left(105 \mathrm{vs} .106 \mathrm{~m}^{2}\right)$, and reduced slightly for the SA inventory (from 132 to $112 \mathrm{~m}^{2}$ ). The scaling exponent $\beta$ confirmed the difference between the two mapping techniques in detecting and mapping the small landslides. The relatively small variations of the scaling parameters $\alpha$ and $\beta$ suggest that the changes introduced in the two inventories by excluding the soils slips affected all landslide sizes. Overall, all the tests outline that the event inventories without the soil slips are more similar that the inventories that contain the soil slips.

Interestingly, the frequency distributions of the NDVI for the event landslides (without the soil slips) in the two inventories are very similar (Fig. 9), with a single mode. The matching between the distributions is better 
for NDVI $<0.10$, indicative of sparsely vegetated or bare ground, and reduced for NDVI $>0.40$, indicative of forested terrain. Analysis of the landslide surface spectral response for the reduced inventories confirmed the inability of the semi-automatic technique to detect consistently the soil slips, in the study area.

\section{Discussion}

The availability of two independent event landslide inventories for the same trigger in the same geographical area (Fig. 3) allowed for a quantitative comparison of the two landslide maps, and for outlining advantages (strengths) and drawbacks (weaknesses) of the methods used to prepare the inventories.

The PI inventory (Fig. 3a) portrays more landslides (51, $8.7 \%$ ) than the SA inventory (Fig. 3b) (Table 1). The difference is larger if the landslides mapped in shadow areas in the SA inventory $(74,13.8 \%)$ are excluded. The investigator could not detect visually most of these landslides on the aerial imagery used to prepare the PI inventory. We explain the larger number of landslides in the PI inventory with the improved resolution of the aerial photographs $(0.27 \times 0.38 \mathrm{~m})$ and the orthophotographs $(\mathrm{GSD}=0.15 \mathrm{~m})$ used for the visual identification of the landslides, compared to the resolution of the satellite imagery used for the semi-automatic mapping $(\mathrm{GSD}=2.0 \mathrm{~m})$. The final post-processing performed to obtain the SA inventory also affected the result. Locally, clumping and vectorization of the landslide information merged multiple, very small landslides in single larger landslides, reducing the total number of the mapped event landslides.

The mismatch index $E=0.71$ confirms that the difference between the two event inventories is significant, but in the range of the differences measured by other investigators that have compared landslide inventories in similar physiographical settings (e.g., Carrara et al., 1992; Galli et al., 2008; Fiorucci et al., 2011). In addition to the causes for the mismatch discussed by these investigators, in our test case the difference is also the result of the non-perfect co-registration of the satellite imagery, particularly in steep terrain, and of the different resolutions of the satellite and the aerial imagery.

Despite the mismatch index $E$, visual inspection of the two inventories at their reference scale $(1: 10000)$ reveals a similar spatial distribution of the event landslides in the two landslide maps (Fig. 3a, b). This is confirmed (i) by the spatial correlation between the two inventories $\left(\mathrm{cc}_{\rho_{1} \rho_{2}}=0.57\right)$, (ii) by the similarities of the double Pareto density functions for the two inventories (Fig. 7), and (iii) by the significant overlap of the NDVI statistics that exhibit similar values and a distinct bivariate distribution (Fig. 8). The bivariate distribution of the NDVI values for the PI inventory indicates that there are two types of land cover in the landslide areas, i.e. sparsely vegetated areas characterized by a low value of the

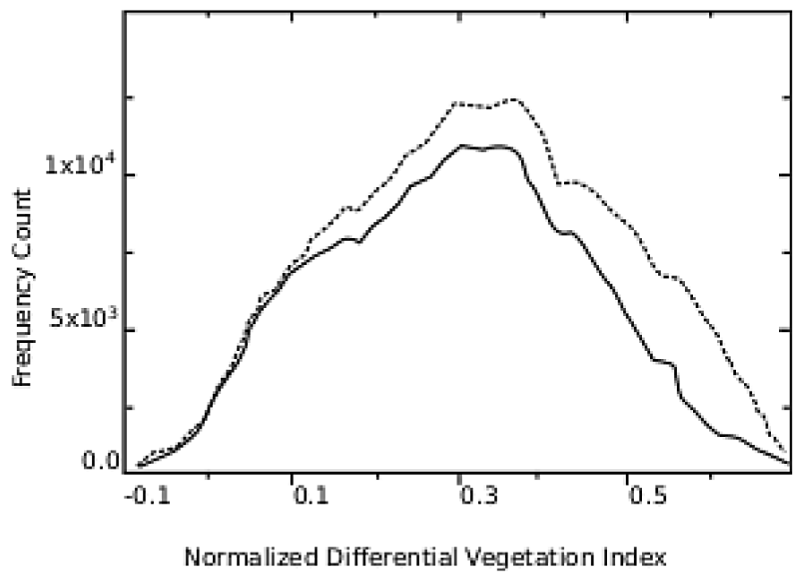

Figure 9. Distribution of NDVI values in the areas covered by the two modified event inventories. Dotted line shows the modified photo-interpreted (PI) inventory. Continuous line shows the modified semi-automatic (SA) inventory.

NDVI, and more densely vegetated areas characterized by a high value of NDVI. The bivariate distribution of the SA inventory is less distinct, and the result of the presence in the mapped landslides of sparsely vegetated areas characterized by low to medium values of NDVI, and of bare soil characterized by very low values of the NDVI. Landslides in the PI inventory that contribute to the right peak of the bivariate distribution (values of NDVI up to 0.4) were not detected by the semi-automatic procedure because they were covered by vegetation. Indeed, the semi-automatic procedure was not trained to detect landslides in vegetated areas, and can detect landslides solely where inside the landslides the soil is bare or the vegetation is sparse.

The semi-automatic technique was able to detect landslides in shadow areas, exploiting the faint, but not completely missing landslide radiometric signature captured by the multispectral satellite image. In the same areas, the visual interpretation of the aerial photographs failed to recognize some landslides, because the aerial imagery was too dark to allow for their visual recognition. The finding outlines an advantage of the multispectral satellite images over panchromatic aerial photographs or orthophotographs for the detection and mapping of event landslides (Mondini et al., 2011). The semi-automatic technique was unable to detect most of the soil slips, which were instead recognized visually on the aerial imagery. Analysis of the NDVI in the soil slips revealed that these landslides where characterized by the presence of vegetation, chiefly grass (NDVI up to 0.4 ) (Fig. 8). For this reason, the soil slips could not be detected by the semi-automatic technique that, as explained before, can only detect landslides where the soil is bare or the vegetation is sparse. We attribute the better results obtained through visual interpretation of the aerial imagery to the fact that the investigator used additional information not available to the 
semi-automatic technique. This additional information used by the investigator could be related e.g. to the local morphology of the areas where the soil slips occurred, to the position of the soil slips in the slope or with respect to the drainage network, or to geometrical relationships (e.g., proximity) between the soil slips and other landslides in the same slope. The result identifies a limitation of current semi-automatic techniques for the detection and mapping of landslides. More advanced automatic techniques that exploit topographic information may mitigate the problem (Mondini et al., 2013).

When considering the two reduced inventories, i.e. the inventories without the soil slips, the spatial density of the event landslides (Fig. 3, Table 1) and the double Pareto probability density functions used to model the distributions of the event landslide areas (Fig. 7, Table 2) are remarkably similar for the two inventories. This indicates that the two landslide maps measure a similar landslide magnitude for the same triggering event (Malamud et al., 2004). Considering that the SA inventory was prepared in a fraction of the time used to prepare the PI inventory ( 24 vs. $160 \mathrm{~h}$ ), we conclude that the semi-automatic technique proved competitive for the rapid mapping of event landslides (Guzzetti et al., 2012). Should a more accurate inventory be required, e.g. for recovery operations or the detailed assessment of residual risk, the SA inventory can be refined through the visual interpretation of the aerial imagery, or the stereoscopic satellite images. The visual interpretation of the aerial imagery allowed for the classification of the different landslide types; this was not possible using the semi-automatic technique.

\section{Conclusions}

For the $25.1 \mathrm{~km}^{2}$ Pogliaschina catchment, in the NW Apennines, northern Italy, we obtained two independent event landslide inventory maps showing landslides triggered by a high-intensity rainstorm that hit the area on 25 October 2011. The first inventory was obtained through the visual interpretation of aerial imagery taken immediately ( 3 days) and shortly (33 days) after the rainfall event. The second inventory was obtained by exploiting a semi-automatic procedure applied to a VHR resolution multispectral satellite image captured 4 days after the rainfall event. We compared the two inventories by exploiting methods already present in the literature and by proposing new qualitative and quantitative criteria. Comparison of the two independent event inventory maps led to the following conclusions:

- The mismatch between the two inventories is significant, but consistent with differences measured by other investigators in similar physiographical areas. The mismatch is attributed to: (i) local co-registration errors between the orthophotographs and the satellite images, (ii) different spatial resolutions of the orthophotographs and the satellite images, (iii) the inability of the semiautomatic technique to map a class of landslides that does not show clear signs in the satellite image, and (iv) the inability of the operator to recognize landslides in shadowed areas.

- Visual inspection and quantitative metrics confirm that the two inventories provide similar landslide spatial distributions, making them equivalent for the implementation of multivariate susceptibility and hazard spatial models.

- The semi-automatic technique, based on the processing of a single satellite image, proved competitive for the detection of the event landslides, but was not capable of classifying the different landslide types. Landslide classification could be performed only through the visual interpretation of the aerial imagery by an expert investigator.

- The reduced time required for the preparation of the inventory using the semi-automatic technique makes this technique better suited for the rapid mapping of landslides immediately after the landslide-triggering event. The visual interpretation of the aerial photographs by an expert investigator produced a more accurate inventory best suited for recovery, reconstruction and planning actions.

Acknowledgements. The research was supported by the Autorità di Bacino Interregionale del Fiume Magra, and by the EU LAMPRE Project (EC contract no. 312384).

Edited by: P. Reichenbach

Reviewed by: two anonymous referees

\section{References}

Antonini, G., Ardizzone, F., Cardinali, M., Galli, M., Guzzetti, F., and Reichenbach, P.: Surface deposits and landslide inventory map of the area affected by the 1997 Umbria-Marche earthquakes, B. Soc. Geol. Ital., 121, 843-853, 2002.

Ardizzone, F., Cardinali, M., Galli, M., Guzzetti, F., and Reichenbach, P.: Identification and mapping of recent rainfall-induced landslides using elevation data collected by airborne Lidar, Nat. Hazards Earth Syst. Sci., 7, 637-650, doi:10.5194/nhess-7-6372007, 2007.

Ayalew, L. and Yamagishi, H.: The application of GIS-based logistic regression for landslide susceptibility mapping in the KakudaYahiko Mountains, Central Japan, Geomorphology, 65, 15-31, 2005.

Bini, M., Chelli, A., Durante, A. M., Gervasini, L., and Pappalardo, M.: Geoarchaeological sea-level proxies from a silted up harbour: a case study of the Roman colony of Luni (Northern Tyrrhenian Sea, Italy), Quatern. Int., 206, 147-157, 2009.

Borga, M., Dalla Fontana, G., Gregoretti, C., and Marchi, L.: Assessment of shallow landsliding by using a physically based model of hillslope stability, Hydrol. Process., 16, 2833-2851, 2002. 
Brardinoni, F., Slaymaker, O., and Hassan, M. A.: Landslide inventory in a rugged forested watershed: a comparison between air-photo and field survey data, Geomorphology, 54, 179-196, 2003.

Canuti, P., Casagli, N., Ermini, L., Fanti, R., and Farina, P.: Landslide activity as a geoindicator in Italy: significance and new perspectives from remote sensing, Environ. Geol., 45, 907-919, 2004

Carrara, A., Cardinali, M., and Guzzetti, F.: Uncertainty in assessing landslides hazard and risk, ITC Journal, 2, 172-183, 1992.

Conti, G. and Fagarazzi, L.: Sustainable Mountain Development and the key - issue of Abandonment of Marginal Rural Areas, PLANUM - The European on Line Journal of Planning, 11, 120, 2004.

Ercanoglu, M. and Gokceoglu, C.: Use of fuzzy relations to produce landslide susceptibility map of a landslide prone area (West Black Sea Region, Turkey), Eng. Geol., 75, 229-250, 2004.

Fiorucci, F., Cardinali, M., Carlà, R., Rossi, M., Mondini, A. C., Santurri, L., Ardizzone, F., and Guzzetti, F.: Seasonal landslides mapping and estimation of landslide mobilization rates using aerial and satellite images, Geomorphology, 129, 59-70, doi:10.1016/j.geomorph.2011.01.013, 2011.

Fisher, R. A.: On the mathematical foundations of theoretical statistics, Philos. T. R. Soc. Lond., 222, 309-368, 1992a.

Fisher, R. A.: The goodness of fit of regression formulae, and the distribution of regression coefficients, J. R. Stat. Soc., 85, 597$612,1992 b$.

Galli, M., Ardizzone, F., Cardinali, M., Guzzetti, F., and Reichenbach, P.: Comparing landslide inventory maps, Geomorphology, 94, 268-289, 2008.

Guzzetti, F., Cardinali, M., Reichenbach, P., and Carrara, A.: Comparing landslide maps: a case study in the upper Tiber River Basin, Central Italy, Environ. Manage., 25, 247-263, 2000.

Guzzetti, F., Mondini, A. C., Cardinali, M., Fiorucci, F., Santangelo, M., and Chang, K. T.: Landslide inventory maps: New tools for an old problem, Earth-Sci. Rev., 112, 42-66, 2012.

Hansen, A.: Strategies for classification of landslides, in: Slope Instability, edited by: Brunsden, D. and Prior, D. B., Wiley, New York, 523-602, 1984.

ISPRA: Carta Geologica d'Italia alla scala 1:50.000, Fogli "Sestri Levante", "Pontremoli", "La Spezia", "Levanto", available at: http://www.isprambiente.gov.it/Media/carg/liguria.html, last access: 8 April 2014, 2013.

Liguria Region geo-portal: available at: http://www.cartografia. regione.liguria.it, last access: 23-June 2014, 2014.

Lira, C., Lousada, M., Falcão, A. P., Gonçalves, A. B., Heleno, S., Matias, M., Pereira, M. J., Pina, P., Sousa, A. J., Oliveira, R., and Almeida, A. B.: The 20 February 2010 Madeira Island flashfloods: VHR satellite imagery processing in support of landslide inventory and sediment budget assessment, Nat. Hazards Earth Syst. Sci., 13, 709-719, doi:10.5194/nhess-13-709-2013, 2013.

Malamud, B. D., Turcotte, D. L., Guzzetti, F., and Reichenbach, P.: Landslide inventories and their statistical properties, Earth Surf. Proc. Land., 29, 687-711, 2004.

Marchi, L., Boni, G., Cavalli, M., Comiti, F., Crema, S., Lucía Vela, A., Marra, F., and Zoccatelli, D.: The flash flood of October 2011 in the Magra River basin (Italy): rainstorm characterization and flood response analysis, Geophysical Research Abstracts, 15, EGU2013-11125, 2013.
Martha, T. R., Kerle, N., Jetten, V., van Westen, C., and Vinod Kumar, K.: Characterising spectral, spatial and morphometric properties of landslides for semi-automatic detection using objectoriented methods, Geomorphology, 116, 24-36, 2010.

McCalpin, J.: Preliminary age classification of landslides for inventory mapping, in: Proceedings 21st annual Engineering Geology and Soils Engineering Symposium, University Press, Moscow, Idaho, 99-111, 1984.

Mondini, A. C., Guzzetti, F., Reichenbach, P., Rossi, M., Cardinali, M., and Ardizzone, F.: Semi-automatic recognition and mapping of rainfall induced shallow landslides using satellite optical images, Remote Sens. Environ., 115, 1743-1757, doi:10.1016/j.rse.2011.03.006, 2011

Mondini, A. C., Marchesini, I., Rossi, M., Chang, K.-T., Pasquariello, G., and Guzzetti, F.: Bayesian framework for mapping and classifying shallow landslides exploiting remote sensing and topographic data, Geomorphology, 201, 135-147, doi:10.1016/j.geomorph.2013.06.015, 2013.

Nale, D. K.: QuickBird - Aerial Photography Comparison Report, EMAP International, 37 pp., 2002.

Pašek, J.: Landslide inventory, International Association Engineering Geologist Bulletin, 12, 73-74, 1975.

Raggi, G.: Neotettonica ed evoluzione paleogeografica PlioPleistocenica del bacino del fiume Magra, Memorie della Societa Geologica Italiana, 30, 35-62, 1985 (in Italian).

Remondo, J., González, A., Diaz de Teran, J. R., Cendrero, A., Fabbri, A., and Chung, C. F.: Validation of Landslide Susceptibility Maps; Examples and Applications from a Case Study in Northern Spain, Nat. Hazards, 30, 437-449, 2003.

Stark, C. P. and Hovius, N.: The characterization of landslide size distributions, Geophys. Res. Lett., 28, 1091-1094, 2001.

Stumpf, A. and Kerle, N.: Object-oriented mapping of landslides using Random Forest, Remote Sens. Environ., 115, 2564-2577, doi:10.1016/j.rse.2011.05.013, 2011

Tarolli, P., Preti, F., and Romano, N.: Terraced landscapes: from an old best practice to a potential hazard for soil degradation due to land abandonment, Antrhopocene, doi:10.1016/j.ancene.2014.03.002, online first, 2014.

Wald, L., Ranchin, T., and Mangolini, M.: Fusion of satellite images of different spatial resolutions: Assessing the quality of resulting images, Photogramm. Eng. Rem. S., 63, 691-699, 1997.

van Westen, C. J., Rengers, N., and Soeters, R.: Use of Geomorphological Information in Indirect Landslide Susceptibility Assessment, Nat. Hazard, 30, 399-419, 2003.

van Westen, C. J., van Asch, T. W. J., and Soeters, R.: Landslide hazard and risk zonation why is it still so difficult?, B. Eng. Geol. Environ., 65, 167-184, 2006.

Web Processing Service (WPS): available at: http://geomorphology. irpi.cnr.it/tools/statistcs-of-landslide-sizes, last access: 23-June 2014, 2014.

Weirich, F. and Blesius, L.: Comparison of satellite and air photo based landslide susceptibility maps, Geomorphology, 87, 352364, 2007.

Wieczorek, G. F.: Preparing a detailed landslide-inventory map for hazard evaluation and reduction, Bulletin of the Association of Engineering Geologists, 21, 337-342, 1984.

White, E. P., Enquist, B. J., and Green, J. L.: On estimating the exponent of power-law frequency distributions, Ecology, 89, 905912, doi:10.1890/07-1288.1, 2008. 